\title{
Measuring leaf area index from colour digital image of wheat crop
}

\author{
BAPPA DAS ${ }^{1}$, R.N. SAHOO ${ }^{1 *}$, SOURABH PARGAL ${ }^{1}$, GOPAL KRISHNA ${ }^{1}$, V.K. GUPTA ${ }^{1}$, R. VERMA ${ }^{2}$ \\ and C. VISWANATHAN ${ }^{2}$ \\ ${ }^{1}$ Division of Agricultural Physics, ${ }^{2}$ Division of Plant Physiology, \\ Indian Agricultural Research Institute, NewDelhi 110012 \\ *Email :rnsahoo.iari@gmail.com
}

\begin{abstract}
Leaf area index ( $\mathrm{LAI})$ is an important physiological trait that determines solar radiation interception and thus biomass. In this study leaf area index (LAI) was estimated from vertical gap fraction derived from top-of-canopy digital colour photography ofwheat canopies. An improved vegetation index, Excess Green minus Excess Red (ExG-ExR) was compared to the commonly used Excess Green (ExG), Excess Red (ExR) and normalized difference (NDI) indices. A histogram-based threshold technique was used to separate green vegetation tissues from background soil in order to derive the canopy vertical gap fraction. LAl derived from the ExG-ExR, ExG indexed image was comparable to the LAl measured using the commercial plant canopy analyzer (LAI-2200,LI-CORInc., USA) $\left(\mathrm{R}^{2}=0.68\right.$ and 0.66 for ExG-ExRand ExG, respectively) with RMSE of 0.63 and 0.79 , respectively.However, NDI was overestimated while Ex Rwas found to be under estimated LAI as compared with that measured using the commercial plant canopy analyzer $\left(R^{2}=0.47\right.$ and 0.35 for NDI and ExR, respectively) with RMSE of 4.09 and 2.19, respectively. Thus, digital photography based ExG-ExRmethod can be used as low cost, non-destructive high through put method for assessing LAl, early vigour and gap fraction of wheat and potentially other cereal crops.
\end{abstract}

Keywords : Leaf area index, colour indices, digital photography, image segmentation, histogram threshold

Leaf area index (LAI) of plants determines radiation interception, latent and sensible heat fluxes, and $\mathrm{CO}_{2}$ exchange between the canopy and the atmosphere as it determines the size of the plant-atmosphere interface. LAI is used as a key input parameter in many crop growth simulation and radiative transfer models. LAI and crop cover fraction are needed for in situ monitoring of crop growth conditions and for developing and validating remote sensing products (Canisius et al., 2010; Liu et al., 2010; Liu and Pattey, 2010). Moreover, measuring the temporal dynamics of LAI is used to calibrate initial crop growth model parameters for predicting biomass (Guerif and Duke, 1998, 2000). Further measurement of LAI also gives an estimate of early vigour which is an important trait that determines biomass accumulation under normal and stress conditions.

Direct methods of LAI measurements are the most accurate but they are destructive, time-consuming, labourintensive and low throughput (Jonckheere et al., 2004).LAI is a dynamic parameter, depends on species, agronomic conditions and developmental stage. Thus, for capturing the nature of spatio-temporal variations in LAI over large number of genotypes over large areas throughout a growing season, alternative high throughput non-destructive methods are required. Faster non-destructive measurements can be made with indirect optical methods using commercial equipment such as the AccuPARPAR/LAI ceptometer (Decagon Devices, 2014, WA) or the LAI-2200 plant canopy analyzer (LI-CORInc, USA, 2009), or by means of hemispherical photography (Liu et al., 2013). The advantages of digital photography over other commercially available non-destructivemethods are that the conditions required operating a digital camera place less restriction on radiation conditions, affordable, amendable to automation, easy to use with minimal trainingand the recorded images can be stored on a computer for later review. This allows more intensive acquisition of crop information over space and time.Moreover, estimation of LAI from digital photography through image thresholding technique has the ability to distinguish between photosynthetic and nonphotosynthetic tissues(Chen et al., 1997; Kucharik et al., 1998; Barclay et al., 2000; Stenberg et al., 2003; Garrigues et al., 2008). So the LAI derived from digital photography is the actual LAI contributing to photosynthesis. Most indirect methods estimate the effective plant area index (PAI) rather than actual leafarea index (LAI) as a result of the contribution of non-photosynthetic tissues, which results 
in overestimation of LAI (Macfarlane et al., 2007). This technique for estimation of LAI is more useful for tall canopies like forest where the direct destructive measurement of LAI is difficult to obtain (Chianucci and Cutini, 2013, Garrigueset al., 2008 and Pueschelet al., 2012).Garrigueset al. (2008) found digital hemispherical photography (DHP)as the most robust optical technique in terms of its low sensitivity to illumination conditions, ability to capture gap fraction over short canopy and independence from ancillary information on canopy optical properties. Keeping these points in view, a study was undertaken to retrieve the leaf area index of wheat crop using colour digital image.

\section{MATERIALS AND METHODS}

\section{Study area}

The experiment was conducted during 2013-14 with 10 genotypeslaidin a randomized block design taking3 replications in the experimental farm of Division of Plant Physiology, Indian Agricultural Research Institute, New Delhi, located at $28^{\circ} 38^{\prime} 23$ " $\mathrm{N}$ latitude and $77^{\circ} 09^{\prime} 27^{\prime \prime} \mathrm{E}$ longitude with altitude of 228.6 meter above mean sea level.

\section{Image acquisition}

Images were acquired using a Canon PowershotG9 (12.1 megapixel, 4000x 3000 resolution, sensor size $25.4 \times$ $43.18 \mathrm{~mm}$ and focal length $35-210 \mathrm{~mm}$ with $6 \mathrm{x}$ optical zoom) digital camera under natural sunlight at solar noon at 40, 70, 90 and 110 days after sowing of wheat crop from 10 different genotypes with 3 replications. Digital camera was mounted one meter above the canopy andthe photos were taken looking vertically downwardbetween $11 \mathrm{a} . \mathrm{m}$. and $1 \mathrm{p}$.m. The colour images were recorded in jpeg format and downloaded to desktop computer for subsequent processing.

The LAI measurements were made at 40, 70, 90 and 110 days after sowing using a plant canopy analyzer (LAI2200 , LI-COR Inc., USA) generally when the sun was low on the horizon. This instrument uses a radiative transfer model to calculate LAI from measurements of intercepted solar radiation. LAI was measured with the sun to backside of the instrument operator and a $90^{\circ}$ view cap $\left(270^{\circ}\right.$ open) was used to block operator's shadow on the sensor. Each transect consisted of one above canopy reading, followed by 4 below-canopy readings made at even intervals across a row.

\section{Colour indices}

Different colour indices were derived from digital photograph using red (R), Green (G) and Blue (B) channels and are listed as below.

The normalized difference vegetation index (NDI) by Perez et al. (2000) uses only green (G) and red (R) channels and is given as

$\mathrm{NDI}=\frac{\mathrm{G}-\mathrm{R}}{\mathrm{G}+\mathrm{R}}$

Woebbecke et al., 1995 proposed excess greenness index (ExG)

$\mathrm{ExG}=2 \mathrm{G}-\mathrm{R}-\mathrm{B}$.

An alternate excess red vegetative index (ExR) was proposed by Meyer et al. (1998) as

$(\mathrm{ExR}=1.4 \mathrm{R} " \mathrm{~B})$

An improved index, ExG-ExR given by Meyer and Neto, (2008) was also used in this study.

Where, R, G and B represent the intensity levels recorded by the red, green and blue channels of the digital camera.

Methodology of generating grey scale images of different indices from digital colour image is given in Fig.1.

\section{Thresholding method}

Thresholding is applied to turn a gray-scale image into a binary image by applying a threshold value. A grayscale value above the threshold is set to one (white color) and a value equal to or below the threshold is set to zero (black color). The key to this method is to select an appropriate threshold value for the task. In this work, we have used a histogram based thresholding technique. Histograms are calculated for the indexed digital photograph and then smoothed wherever required with moving average technique to remove noise. The next step is to determine a threshold from the histogram. For ExG-ExR, ExG and NDI indexed images, the pixels of crop cover elements have a larger greenness and are represented on the higher side of the histogram but the reverse is true for ExR indexed images (Fig. 2). This procedure was implemented using digital image processing software ENVI (version 4.8) software.

\section{Estimation of LAI from gap fraction}

The LAI derived from optical instruments by measuring the gap fraction can be calculated by inverting Beer's law:

$P_{0}(\theta)=e^{-G(\theta) \Omega(\theta) L A I / \cos \theta}$ 


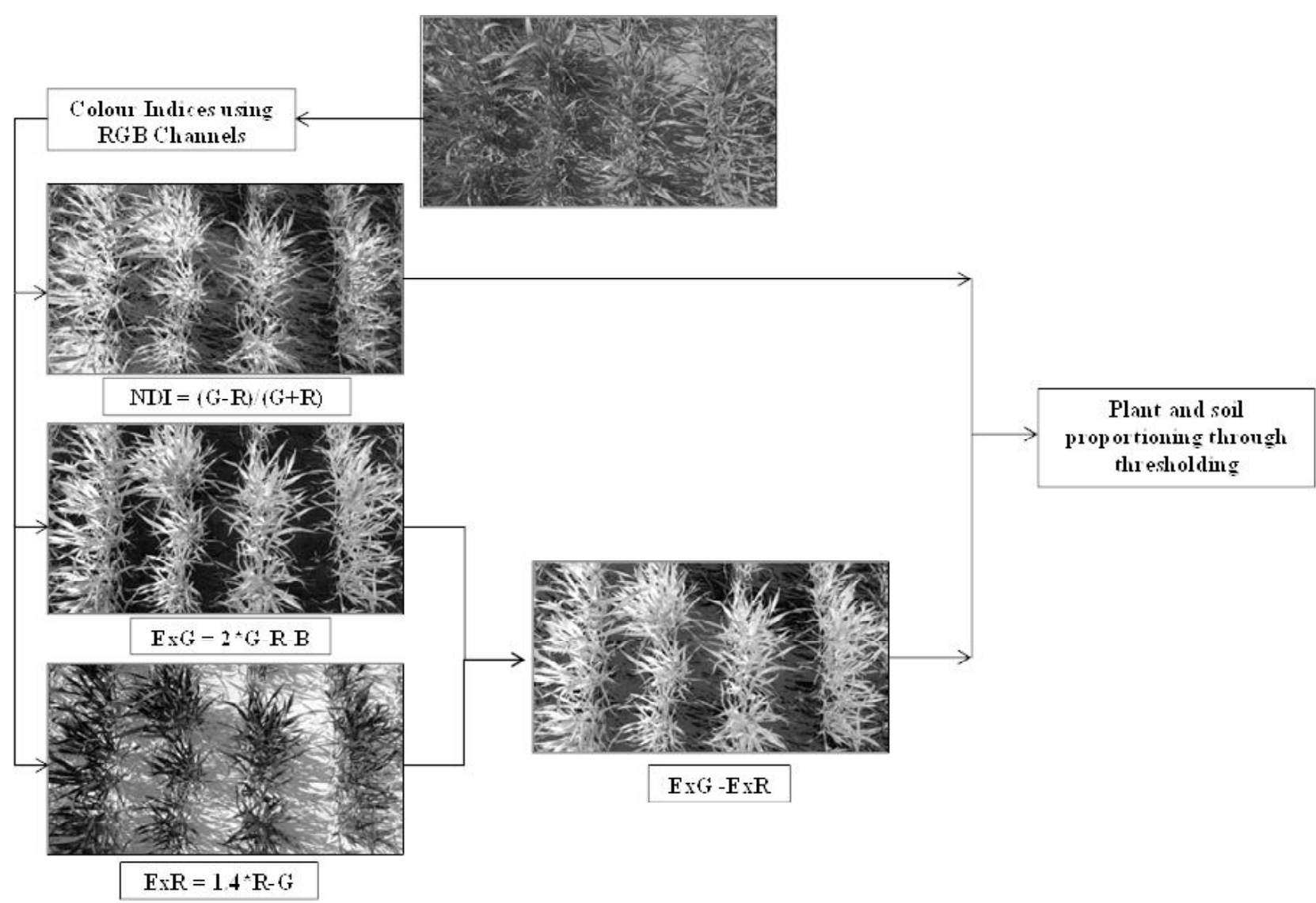

Fig. 1: Methodology of generating tonal images of different indices from digital image

where $P_{o}(\theta)$ is the canopy gap fraction, $G(\theta)$ is the foliage projection coefficient for the plane perpendicular to direction $\theta$, and $\Omega(\theta)$ is the foliage clumping index at zenith angle $\theta$. LAI is the leaf area index, including foliar and woody materials. The clumping index, $\Omega(\theta)$, is the ratio of effective plant or leaf area index to the actual plant or leaf area index, with $\Omega(\theta)$ equal to unity indicating a random canopy, $\Omega(\theta)$ greater than unity implies an evenly distributed canopy, and $\Omega(\theta)$ less than unity represents a canopy with clumped foliage. For agricultural applications, Demarez et al. (2008) found that the use of the clumping index improves LAI measurements for corn but it also causes systematic LAI overestimation for wheat and sunflower. The cosine term in this equation can be omitted because it equals 1 at $\theta=0^{\circ}$.

Assuming the foliage is azimuthally uniform and spatially randomly distributed, the expression for LAI is given by inverting equation (4) as

$$
\mathrm{LAI}=\frac{-\cos (\theta) \ln \mathrm{P}_{0}(\theta)}{\mathrm{G}(\theta)}=\frac{-\ln \mathrm{P}_{0}(\theta)}{\mathrm{k}(\theta)}
$$

Where, $\mathrm{k}(\theta)$ is canopyextinction coefficient.

When a photograph is taken looking vertically downward (i.e., $\theta=0^{\circ}$ ), vertical gap fraction can be directly measured by calculating the proportion of background pixels (including non-green leaf materials) to the total pixels within the frame of the photo. A spherical LIDF is considered a good first-order approximation for crop canopies, in which case $\mathrm{G}$ is equal to 0.5 at any direction (Goudriaan, 1988). LAI is estimated from the vertical gap fraction obtained from digital photography looking vertically downward, assuming spherical LIDF as follows:

$$
\mathrm{LAI}=-2 \ln \left[\mathrm{P}_{0}(\theta)\right]
$$

\section{RESULTS AND DISCUSSION}

\section{LAI and gap fraction}

The LAI, irrespective of genotypes, increased from 40 to 90 DAS followed by a decline at harvest (130 DAS) (Fig.3). Leaf senescence with the dying of lower leaves during later part of the crop growth cycle caused a reduction in LAI after 90DAS (Sinclair, 1994). The gap fraction estimated from ExG-ExR indexed image shows opposite trend of LAI profile (Fig.3). At the initial stage the gap fraction was high due to poor canopy coverage, then it decreased to minimum 

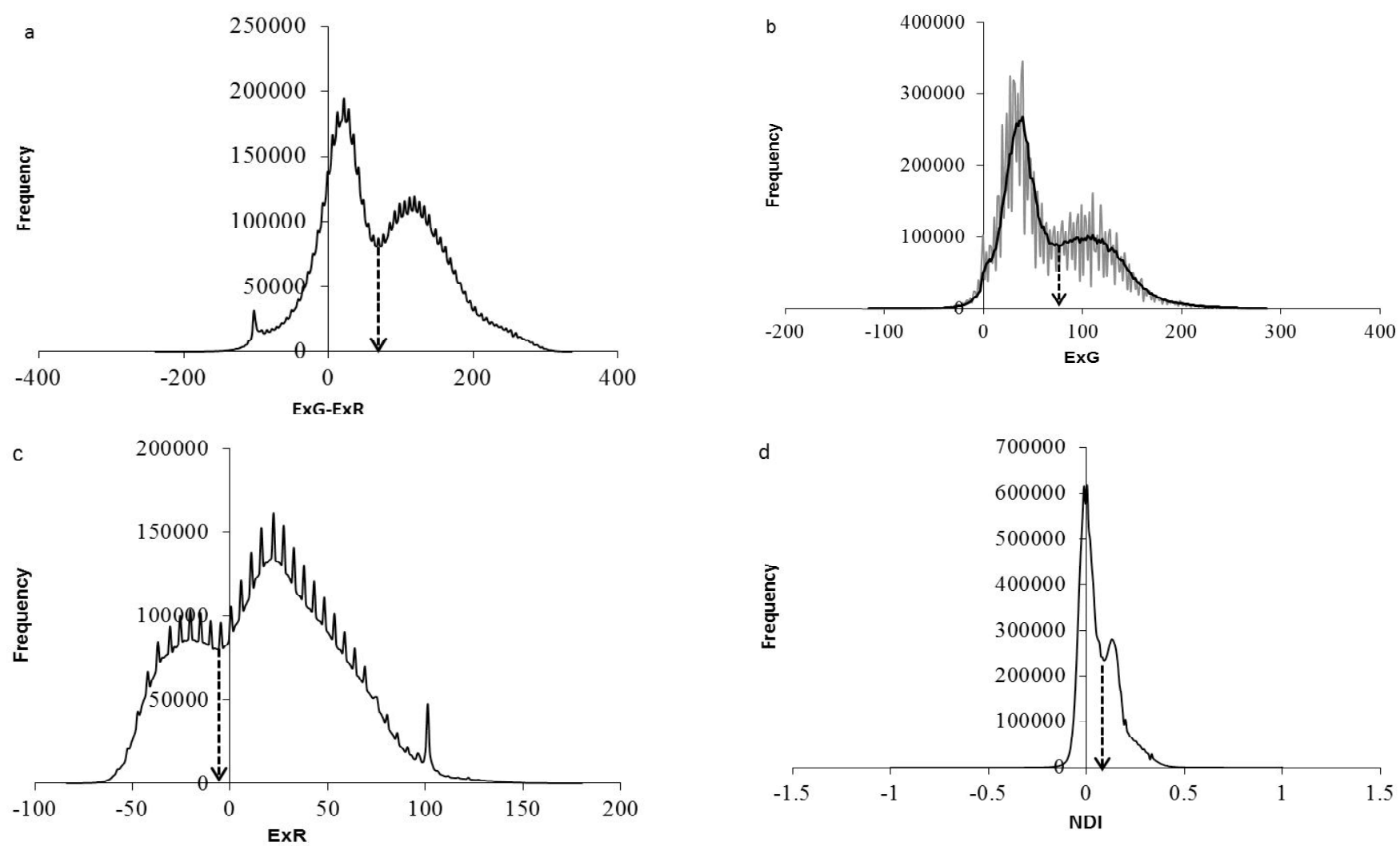

Fig. 2: Determination of the threshold for image segmentation: (a) ExG-ExR, (b) ExG, (C) ExR and (d) NDI
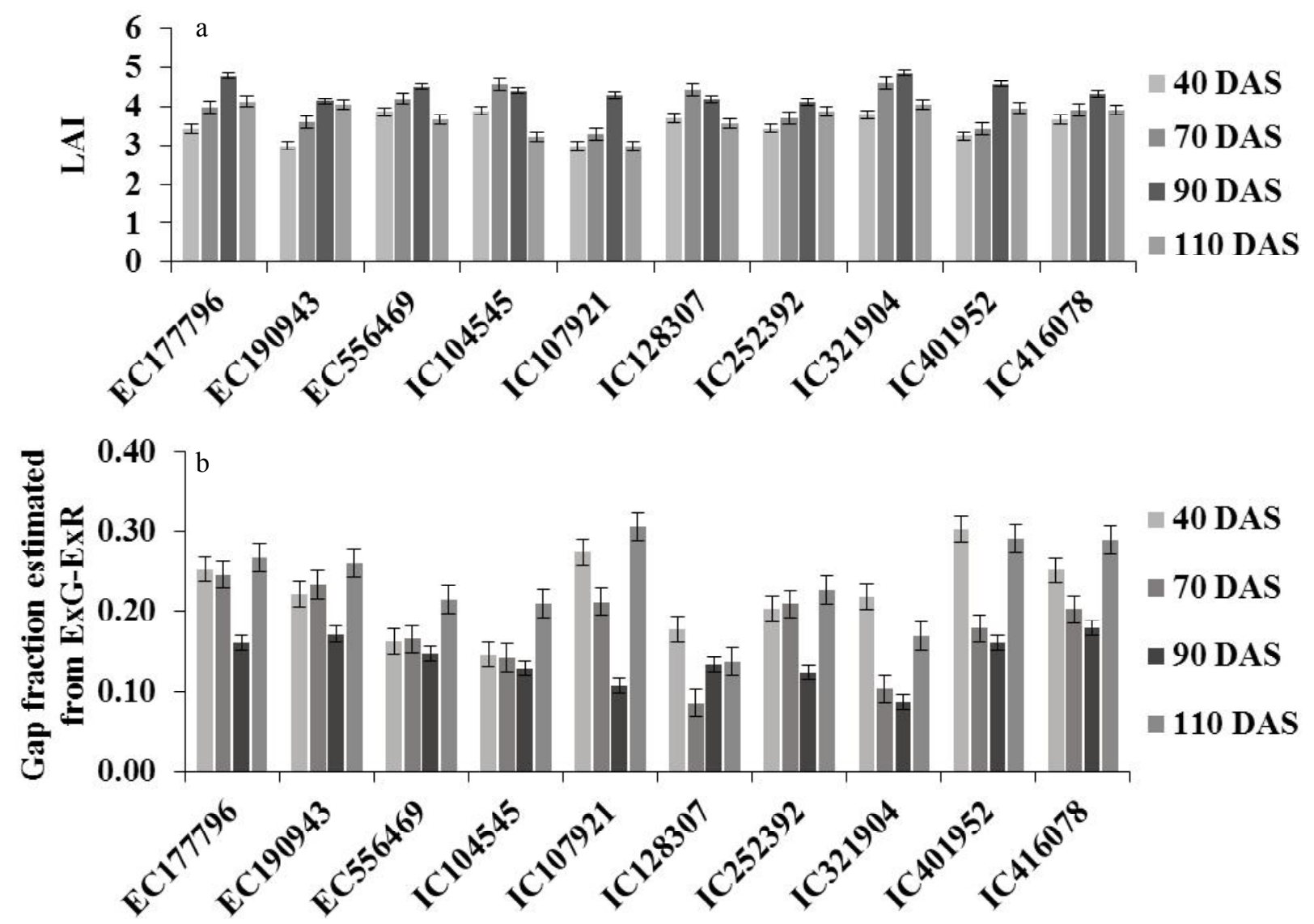

Fig. 3: Profile of (a) LAI measured by canopy analyzer and (b) gap fraction estimated from ExG-ExR indexed image 

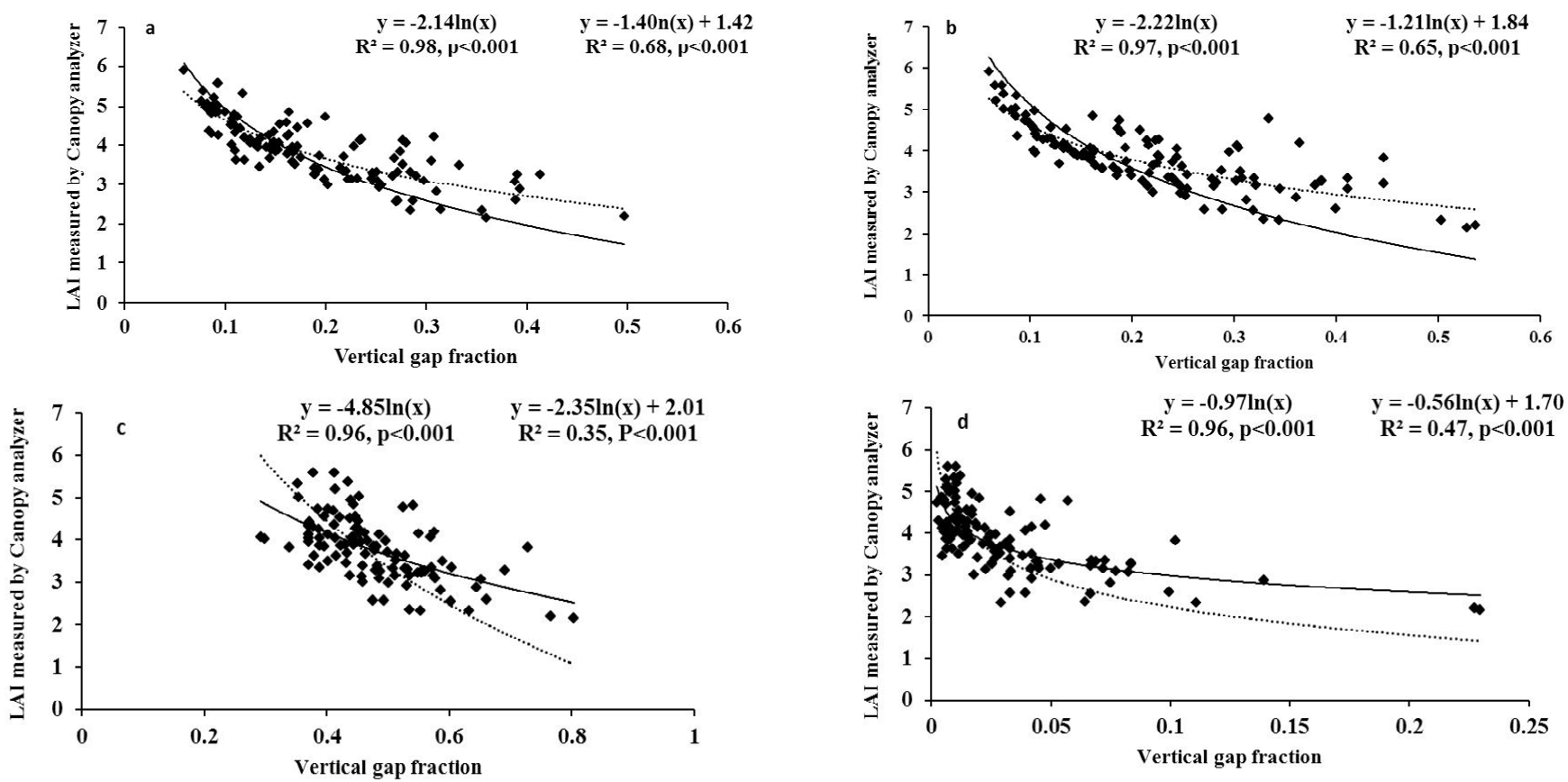

Fig. 4: The relationship between vertical gap fraction derived from (a) ExG-ExR, (b) ExG, (c) ExR and (d) NDI indexed image and LAI measured by the LAI-2200. The solid and dotted lines represent trend lines with and without intercept, respectively.
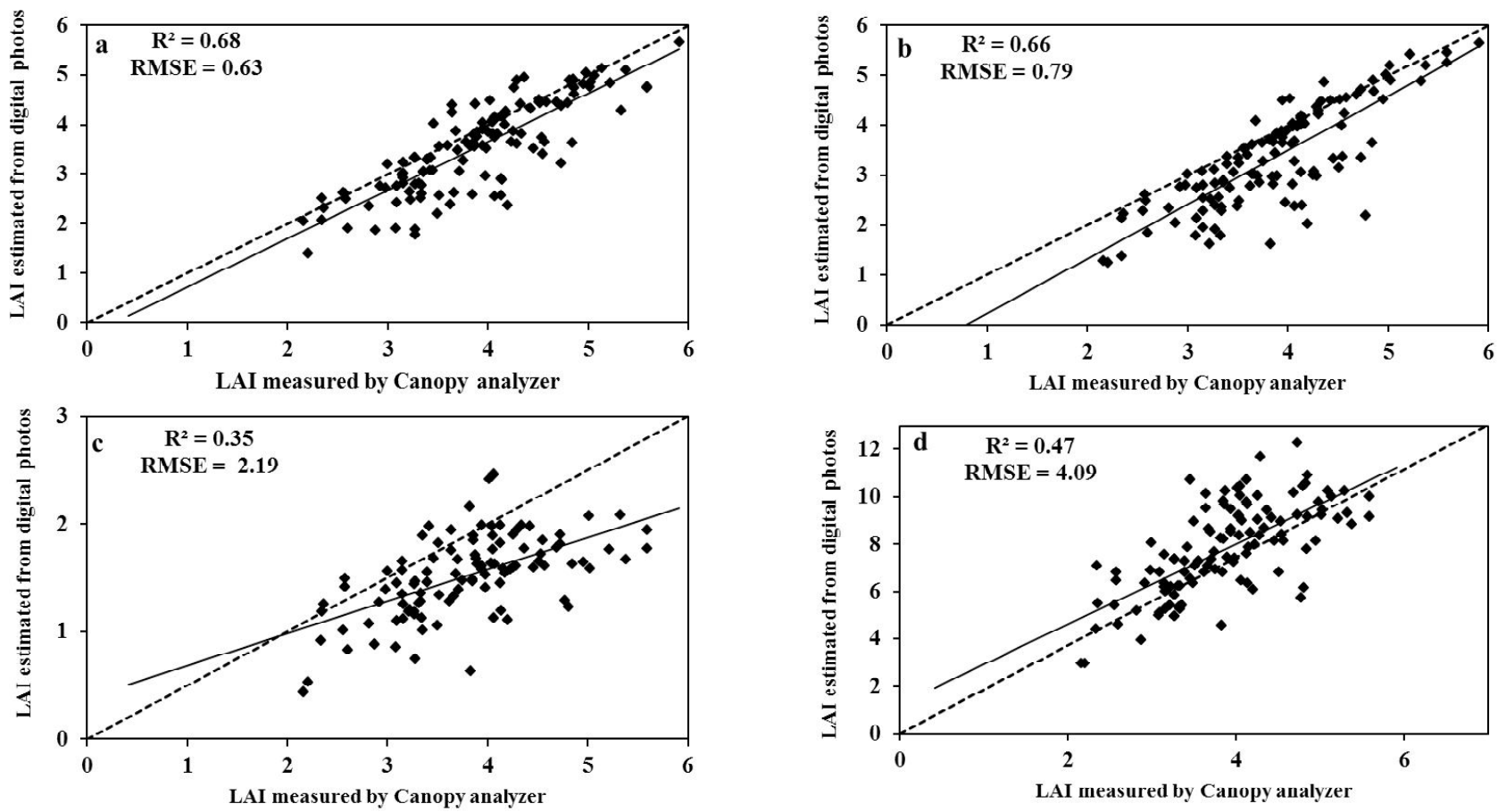

Fig. 5: Comparison of LAI measured by the LAI-2200 and derived from (a) ExG-ExR, (b) ExG, (C) ExR and (d) NDI indexed image at 90 DAS and again it increased with the drying of lower leaves at 130 DAS. It showed greater variation among the genotypes indicating promise of better discrimination of genotypes for rate of senescence. Irrespective of the indices used, the measured LAI and estimated gap fraction was found to follow a logarithmic relationwith a high level of significance $(p<0.001)$ (Fig.4). The gap fraction showed a decreasing trend with increase in LAI. Nielsen et al., (2012)

reported an increasing exponential trend of crop cover fraction with LAI for wheat crop.Liu and Pattey, (2010) also reported a logarithmic relationship between LAI measured with the LAI-2000 and the vertical gap fraction derived from digital photographs.

\section{Extinction coefficient}

The extinction coefficient (the (1/Slope) of LAI 
measured by Canopy analyzer vs Vertical gap fraction when the intercept is set to as zero)derived from ExG-ExR and ExG indexed images were equal to 0.47 and 0.45 , which was close to the assumed value of 0.5 for a spherical LIDF. But the extinction coefficient derived from NDI indexed image was found to be much higher than assumed value (1.04), while it was under estimated in case of ExR indexed image (0.21).

\section{Relationship between measured and estimated LAI}

LAI derived from the ExG-ExR andExG indexed images were comparable to the LAI measured using commercial plant canopy analyzer $\left(\mathrm{R}^{2}=0.68\right.$ and 0.66 for ExG-ExR and ExG, respectively) with RMSE of 0.63 and 0.79 , respectively (Fig.5). Whereas NDI over estimated, while ExR under estimated LAI $\left(\mathrm{R}^{2}=0.47\right.$ and 0.35 for NDI and ExR, respectively) with RMSE of 4.09 and 2.19, respectively.

\section{CONCLUSION}

In this study, commonly available digital camera is used to record plant canopy images. Colour visible image processing technique (ExG-ExR) used in this study has shown a good potential to estimate LAI of wheat crop. Thus we propose digital photography can be used for estimating LAI and gap fraction of wheat crop as this approach in nondestructive, high throughput, low cost and provides opportunity for achieving the images for later analysis.Further, estimation of LAI using commercial plant canopy analyzers requires sufficiently large plot size. Often in large scale germplasm evaluation and evaluation of early generation breeding population, it is not possible to use large plot size. The image based LAI estimation method developed in this study can be used effectively for estimation of plants in few rows. Thus, this method will be useful for breeders and plant physiologist interested in large scale germplasm evaluation and evaluation of early generation breeding population.

\section{ACKNOWLEDGEMENTS}

The authors acknowledge the grant received from ICAR (NASF) under the project "Phenomics of moisture deficit and low temperature stress tolerance in rice" for carrying out the present work. First author also acknowledges the fellowship received from CSIR, New Delhi, India to undertake this research work as part of Ph.D.

\section{REFERENCES}

Barclay, H.J., Trofymow, J.A., andLeach, R.I., (2000). Assessing bias from boles in calculating leafarea index in immature
Douglas-fir with the LI-COR canopy analyzer. Agric. Forest Meteorol., 100(2-3); 255-260.

Canisius, F., Fernandes, R. and Chen, J., (2010). Comparison and evaluation of Medium Resolution Imaging Spectrometer leaf area index products across a range of land use. Rem. Sens. Environ., 114: 950-960.

Chen, J.M., Rich, P., Gower, S.T., Norman, J.M., and Plummer, S., (1997). Leaf area index of boreal forests: theory, techniques and measurements. J.Geophys. Res., 102 (D24):29429-29443.

Chianucci, F., and Cutini, A., (2013). Estimation of canopy properties in deciduous forests with digital hemispherical and cover photography. Agric. For. Meteorol., 168: 130-139.

Decagon Devices (2014). AccuPAR PAR/LAI ceptometer Instruction Manual, pp. 82.

Demarez, V., Duthoit, S., Baret, F., Weiss, M. and Dedieu, G., (2008). Estimation of leaf area and clumping indexes of crops with hemispherical photographs. Agric. Forest Meteorol., 148: 644-655.

Garrigues, S., Shabanov, N., Swanson, K., Morisette, J., Baret, F., and Myneni, R., (2008). Intercomparison and sensitivity analysis of Leaf Area Index retrievals from LAI-2000, AccuPAR, and digital hemispherical photography over croplands. Agric. For. Meteorol., 148:1193-1209.

Goudriaan, J., (1988). The bare bornes of leaf-angle distribution in radiation models for canopy photosynthesis and energy exchange. Agric. Forest Meteorol.,43: 155-169.

Guerif, G. and Duke, C., (1998). Calibration of the SUCROS emergence and early growth module for sugar beet using optical remote sensing data assimilation. Eur.J. Agron.,9: 127-136.

Guerif, G., and Duke, C., (2000). Adjustment procedures of a crop model to the site specific characteristics of soil and crop using remote sensing data assimilation. Agric. Ecosyst. Environ.,81: 57-69.

Jonckheere, I., Fleck, Nackaerts, K., Muys, B., Coppin, P., Weiss, M. and Baret, F., (2004). Review of methods for in situ leaf area index determination. Part I. Theories, sensors and hemispherical photography. Agric. For. Meteorol., 121: 19-35.

Kucharik, C.J., Norman, J.M., and Gower, S.T., (1998). Measurements of branch area and adjusting leaf area 
index indirectmeasurements. Agric. Forest Meteorol.,91 (1-2): 69-88

LI-COR, (2009). LAI-2200 Plant CanopyAnalyser Instruction Manual, pp.217.

Liu, J. and Pattey, E., (2010). Retrieval of leafarea index from topof-canopy digital photography over agricultural crops. Agric. For. Meteorol.,150: 1485-1490.

Liu, J., Pattey, E., and Admiral, S., (2013). Assessment of in situ crop LAI measurement using unidirectional view digital photography. Agronomy, 169: 25-34.

Liu, J., Pattey, E., Miller, J.R., McNairn, H., Smith, A. andHu, B., (2010). Estimating crop stresses, aboveground dry biomass and yield of corn using multi-temporal optical data combined with a radiation use efficiency model. Rem. Sens. Environ., 114: 1167-1177.

Macfarlane, C., Hoffman, M., Eamus, D., Kerp, N., Higginson, S., McMurtrie, R., and Adams, M., (2007). Estimation of leaf area index in eucalypt forest using digital photography. Agric. For. Meteorol.,143(3): 176-188.

Meyer, G.E., and Neto, J.C., (2008). Verification of color vegetation indices for automated crop imaging applications. Comput. Electron. Agric., 63:282-293.

Meyer, G.E., Hindman, T.W., and Lakshmi, K., (1998). Machine vision detection parameters for plant species identification. In: Meyer, G.E., DeShazer, J.A. (Eds.),
Precision Agriculture and Biological Quality, Proceedings of SPIE. vol. 3543, Bellingham, WA, pp. $327-335$.

Nielsen, D., Miceli-Garcia, J.J. and Lyon, D.J. (2012). Canopy Cover and Leaf Area Index Relationships for Wheat, Triticale, and Corn. Agron. J.,104: 1569-1573.

Perez,A.J., Lopez, F., Benlloch, J.V., and Christensen, S., (2000). Color and shape analysis techniques for weed detection in cereal fields. Comput. Electron. Agric., 25: 197-212.

Pueschel, P., Buddenbaum, H., and Hill, J., (2012). An efficient approach to standardizing the processing of hemispherical images for the estimation of forest structural attributes. Agric. For. Meteorol., 160: 1-13.

Sinclair, T.R., (1994). Limits to crop yield. In: Boote, K.J., Bennett, J.M., Sinclair, T.R., Paulsen, G.M. (Eds.), Physiology and Determination of Crop Yield. ASA, CSSA, SSSR, Madison WI, pp. 200-220.

Stenberg, P., Nilson, T., Smolander, S., and Voipio, P., (2003). Gap fraction based estimation of LAI in scots pine stands subjected to experimental removal of branches and stems. Canadian J. Remote Sens., 29: 363-370.

Woebbecke, D.M., Meyer, G.E., Von Bargen, K., and Mortensen, D.A., (1995). Colorindices for weed identification under various soil, residue, and lighting conditions. Trans. the ASAE,38:259-269. 